\title{
REACTION SYNTHESIS/DYNAMIC COMPACTION OF TITANIUM CARBIDE AND TITANIUM DIBORIDE
}

\author{
M.A. MEYERS* , J.C. LA SALVIA*, L.W. MEYER**, D. HOKE* and \\ A. NIILER*** \\ "Department of Applied Mechanics and Engineering \\ Sciences, University of California, San Diego, La Jolla, CA \\ 92093-0411, U.S.A. \\ ** Fraunhofer Institut für Angewandte Materialforschung, \\ Bremen, Germany \\ ***U.S. Army Ballistic Research Laboratory, Aberdeen, MD, \\ U.S.A.
}

\begin{abstract}
Titanium carbide and titanium diboride were synthesized by self-propagating combustion reactions and densified by a high-speed forging technique, in which a hammer strikes the hot and porous ceramic $\left(\mathrm{T} \sim 2000^{\circ} \mathrm{C}\right.$ ) at velocities in the range $5-15 \mathrm{~m} / \mathrm{s}$. Compacts with densities higher than $96 \%$ of the theoretical density and diameters close to $10 \mathrm{~cm}$ were produced by this method. Optical and scanning electron microscopy of the consolidated material were carried out, revealing a grain size of approximately $44 \mu \mathrm{m}$ for $\mathrm{TiC}$ and $15 \mu \mathrm{m}$ for $\mathrm{TiB}_{2}$; these grains were equiaxed, indicating that crystallization (or recrystallization) occurred after the densification process. The quasistatic and dynamic compressive strengths were established and compared to those of hot-pressed material produced by CERCOM. For $\mathrm{TiB}_{2}$, the strengths were approximately $1.8 \mathrm{GPa}$, while for TiC the quasistatic $\left(10^{-3} \mathrm{~s}^{-1}\right)$ and dynamic $\left(10^{2} \mathrm{~s}^{-1}\right)$ strengths were 1.7 and $2.2 \mathrm{GPa}$, respectively.
\end{abstract}

\section{Introduction}

Reaction synthesis, combustion synthesis, or self-propagating high-temperature synthesis (SHS) is a relatively new method to produce ceramics and intermetallics that uses the highly exothermic reactions between constituent elements and/or compounds to propagate a reaction, once it is initiated. Figure 1 shows the fundamental elements of a propagating reaction front. A porous mixture of $A$ and $B$ reacts, forming $A_{x} B_{y}$. The exothermic reaction generates heat at the rate governed by the kinetics of reaction. This heat is conducted away by the unreacted and reacted materials. The heats of reaction are typically $10^{3} \mathrm{~J} / \mathrm{g}$ and the velocities of reaction range from 0.1 to $25 \mathrm{~cm} / \mathrm{s}$. Currently, research on combustion synthesis is carried out primarily in the Soviet Union, Japan, and U.S.A. In the Soviet Union, Merzhanov initiated in 1967 a major program, at the Soviet Institute of Chemical Physics and over 300 different materials have been synthesized by this method $/ 1 /$. In the U.S., Munir $/ 2 /$ and co-workers have carried out extensive investigations. The product of combustion reactions is most of the time highly porous and additional consolidation steps are required to produce fully densified material. At the U $S$. Army Ballistic Research Laboratory, Niiler and co-workers /3/ have explosively consolidated titanium carbide and titanium diboride shortly $(\sim 10$ seconds) after the combustion reaction was completed. In the research program described herein the explosive compaction stage was replaced by dynamic compaction in a high-speed DYNAPAK forging machine.

\section{Experimental Techniques}

Elemental powders (titanium carbon, boron) and $\mathrm{TiB}_{2}$ were used with the following sizes: 
Ti $(<44 \mu \mathrm{m})$, graphite $(<2 \mu \mathrm{m})$, boron $(<44 \mu \mathrm{m}), \mathrm{TiB}_{2}(<44 \mu \mathrm{m})$. These powders were mixed in a ball mill for four hours. The following mixtures were prepared:

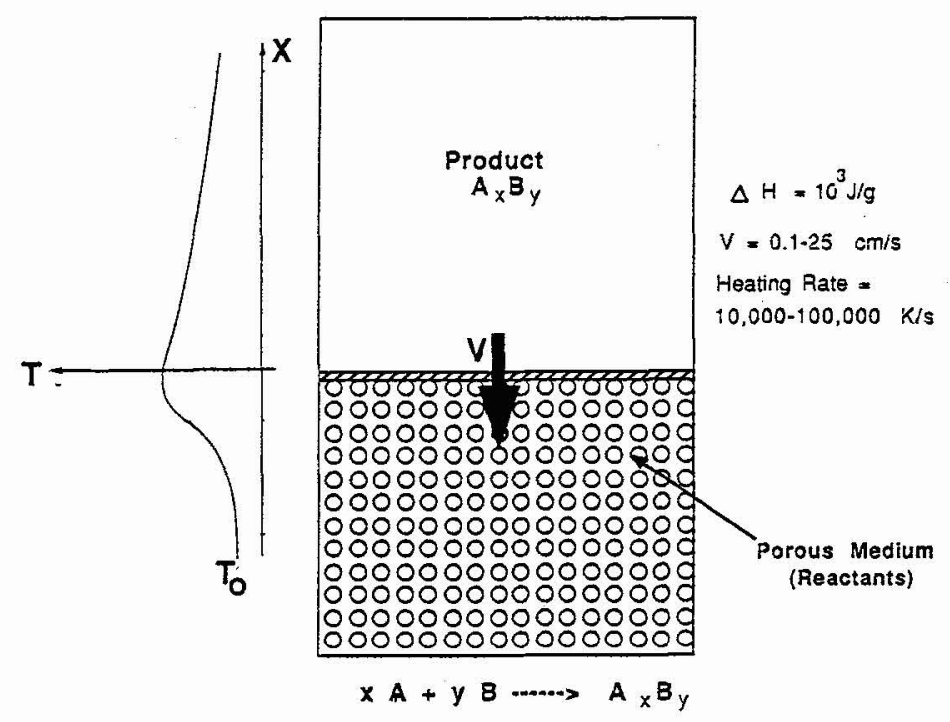

Fig. 1 Schematic representation of combustion synthesis process and of the associated temperature profile.

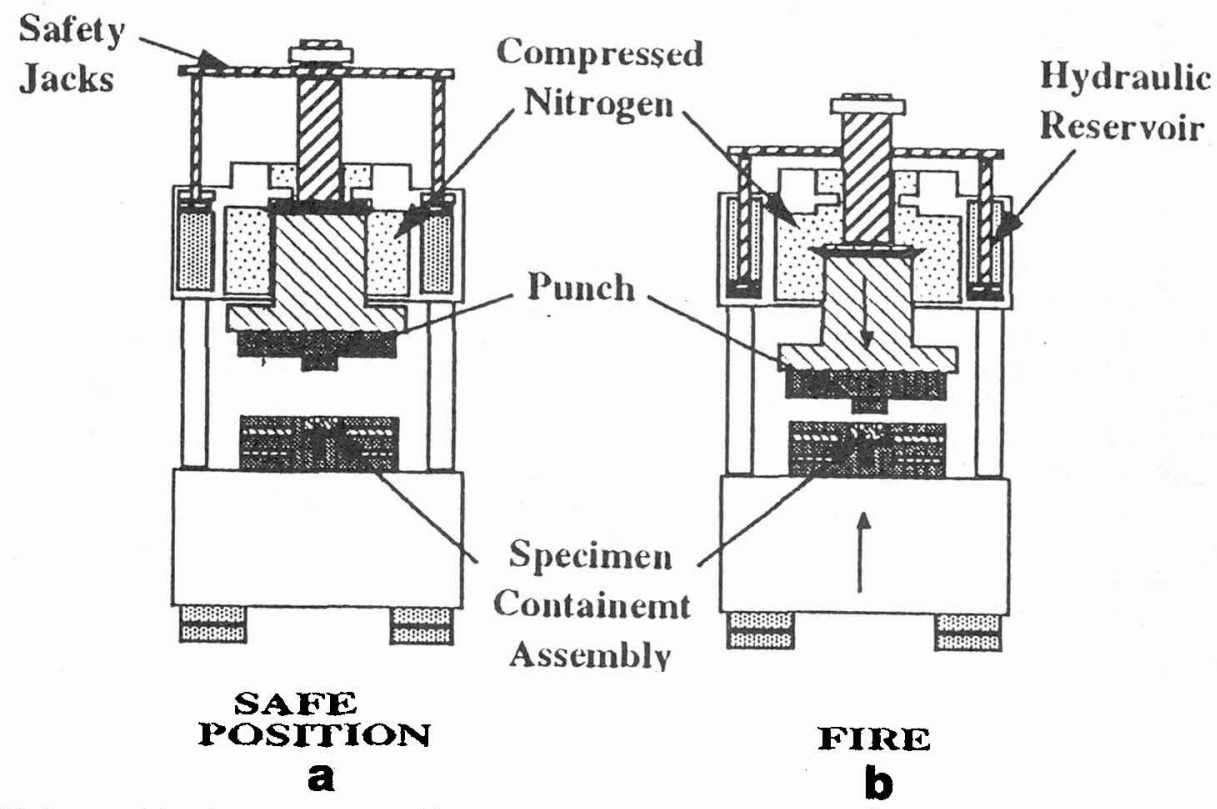

Fig. 2 High-speed forging machine and its essential components; (a) loading position; (b) firing position. 
1) $\mathrm{Ti}+0.9 \mathrm{C}$

2) $\mathrm{Ti}+2 \mathrm{~B}+22.5 \mathrm{wt} \% \mathrm{TiB}_{2}$

3) $\mathrm{Ti}+0.9 \mathrm{C}+(1.5-20) \mathrm{wt} \% \mathrm{Ni}$

4) $\mathrm{Ti}+2 \mathrm{~B}+22.5 \mathrm{wt} \% \mathrm{TiB}_{2}+1.5 \mathrm{wt} \% \mathrm{Ni}$.

These mixtures were uniaxially pressed into green compacts having a density of $\sim 60 \%$ of the theoretical density. The green compacts were placed in a reaction/consolidation fixture with proper lateral and bottom insulation, which was positioned in the lower die of a high-speed forging machine. Figure 2 shows the DYNAPAK machine, which consists of an upper punch driven by compressed nitrogen, impacting the specimen containment assembly at velocities ranging from 5 to $15 \mathrm{~m} / \mathrm{s}$. The energy delivered by the machine is $25 \mathrm{~kJ}$. Figure 2 shows two positions of the machine: (a) in the loading position and (b) at the moment of impact.

The specimens were ignited by a rocket ignitor placed on loose powder on top of the green compact, as shown in Figure 3. After the reaction was completed (1-10 seconds) the upper die was activated and the specimen was compacted. The compact was then removed from the lower die and placed in a furnace at a temperature of $1200^{\circ} \mathrm{C}$ under argon atmosphere. The specimens were allowed to cool over a period of 24 hours.

After cooling, the specimens were sliced by a diamond saw. Specimens for mechanical testing were cubic (TiC: $6 \times 6 \times 6 \mathrm{~mm}$ ) or tetragonal (TiB $2: 4 \times 4 \times 8 \mathrm{~mm}$ ). Quasistatic compressive tests were carried out at IFAM using special compression plates with a self-alignment feature and using $\mathrm{MoS}_{2}$ as lubrication. Dynamic tests were performed using a drop hammer machine at IFAM and a compressional Hopkinson bar at UCSD. A resistive gage was attached to the side of specimen to record the strain, while the stress is given by the amplitude of the transmitted pulse, with the appropriate impedance correction.

\section{Results and Discussion}

Figure 4 shows two discoid specimens made by the SHS/DC method. At first, profuse cracking was present (Fig. 4(a)), which was gradually reduced by improving thermal insulation and the rate of cooling of compacts. These cracks were primarily produced by thermal gradients in the specimens. For comparison purposes, hot pressed titanium carbide and titanium diboride were obtained from CERCOM, Vista, CA. Figure 5 shows the microstructure of SHS/DC and HP titanium carbide. Both exhibit equiaxed grains, with the grain size of the SHS/DC TiC being slightly larger ( $44 \mu \mathrm{m}$ versus $30 \mu \mathrm{m})$. The porosity of the hot pressed TiC is higher than the one of SHS/DC, in spite of the higher density of the latter (100\% vs. 96\%). This is ascribed to the presence of heavier elements (tungsten and iron) in the hot pressed TiC. Vecchio et al. $/ 4 /$, in a separate publication, analyze the composition of second phase particles in hot pressed TiC.

$\mathrm{TiB}_{2}$ was combustion synthesized with the addition of $20 \mathrm{wt} \%$ of the inert phase. $\mathrm{TiB}_{2}$ powder was added to the reacting powders in order to decrease the overall temperature and reaction velocity. Figure 6(a) shows this material. A few microcracks can be seen in the microstructure, marked by arrows. The addition of $1.5 \mathrm{wt} \% \mathrm{Ni}$ created a more favorable microstructure. In Figure 6(b) this microstructure is shown. A thin nickel grain boundary layer is evident; the microcracks are absent.

The addition of nickel to titanium carbide created a cermet. Experiments were conducted with additions of $20 \%$ (Fig. 7(a)) and 5\% (Fig. 7(b)). The microstructure reveals some unique features which might lead to enhanced toughness. It consists of spheroidal TiC grains surrounded by a Ni-Ti alloy. Ni$\mathrm{Ti}$ is known to undergo a reversible martensitic transformation, and the microstructures shown in Fig. 7 could have very unique thermomechanical response.

While the energy of the DYNAPAK machine was sufficient to densify TiC without the addition of nickel, for $\mathrm{TiB}_{2}$ the density achieved with the $\mathrm{Ti}+\mathrm{B}+\mathrm{TiB}_{2}$ mixture was approximately $88 \%$. This decrease in maximum density is due to the presence of the inert phase, that reduces the maximum temperature of the synthesized product. Figure 8 shows how the addition of nickel and additional lateral confinement led to the increase in density. The highest densities achieved are $96 \%$.

Table I summarizes the principal results of mechanical tests. 


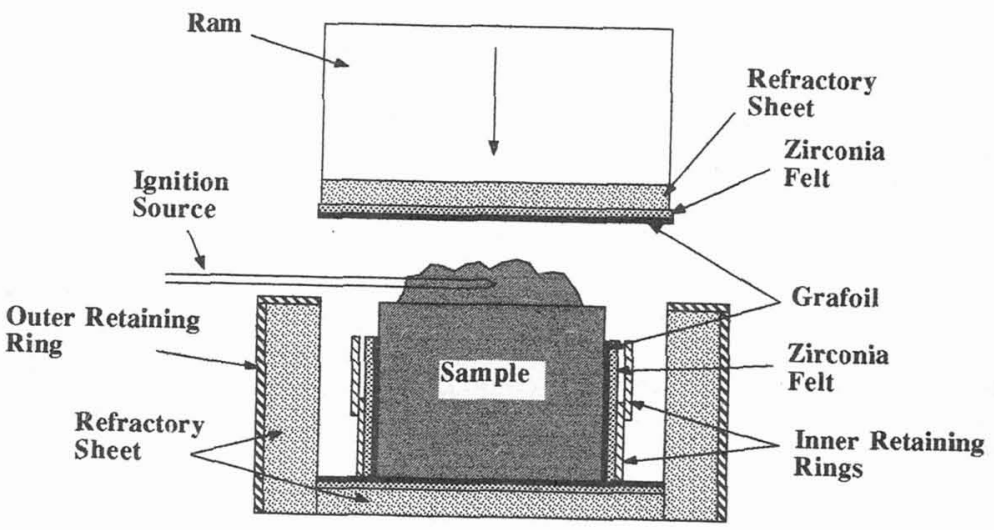

Fig. 3 Specimen containment assembly.

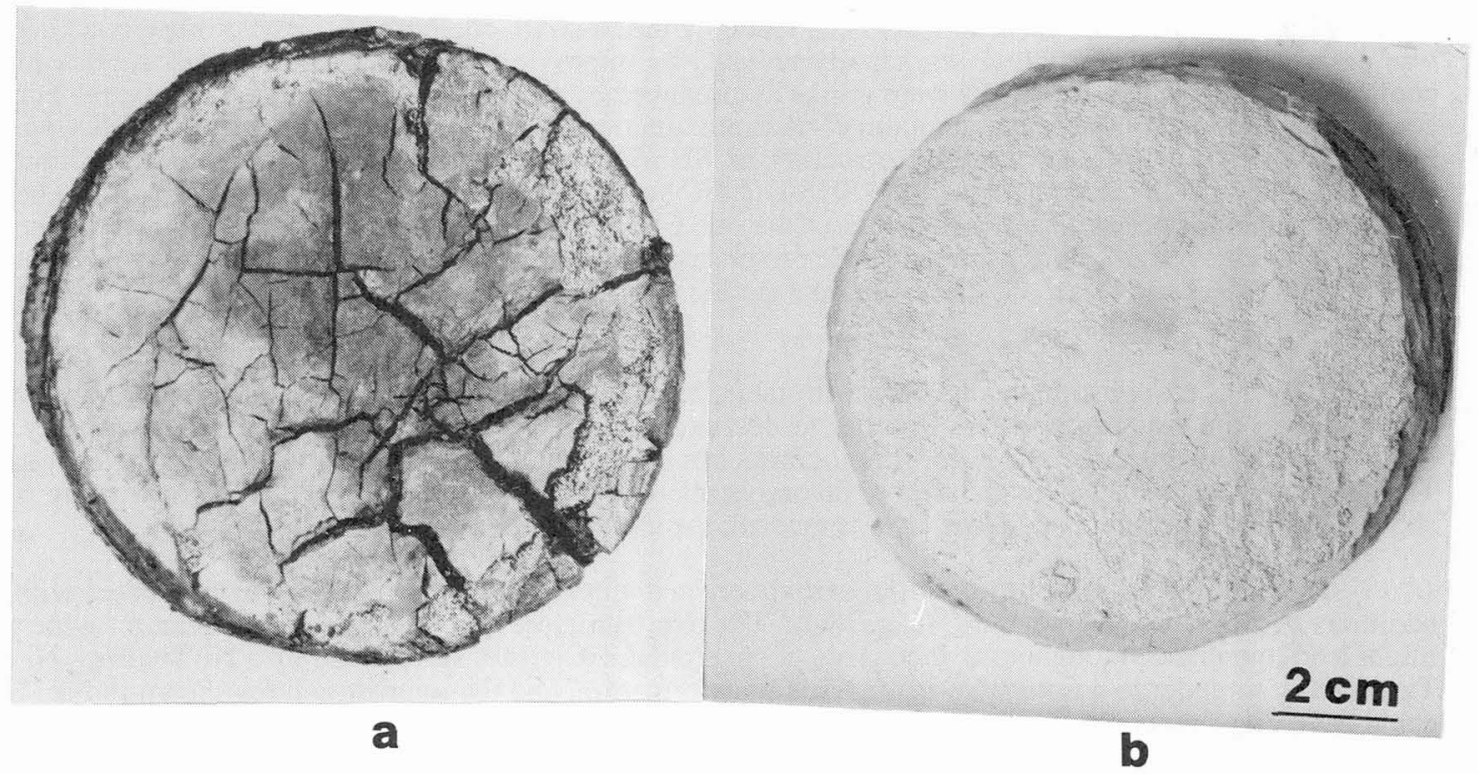

Fig. 4 Specimens made by SHS/DC

(a) early specimen with profuse cracking;

(b) after crack reduction. 


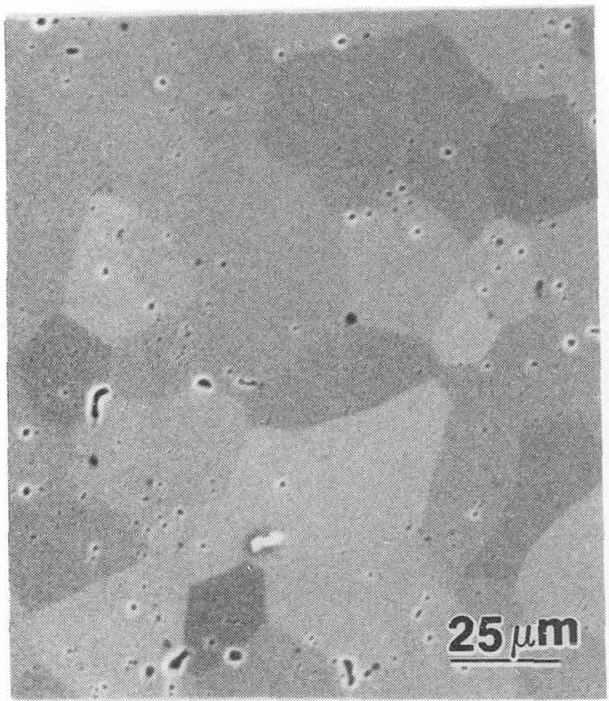

a

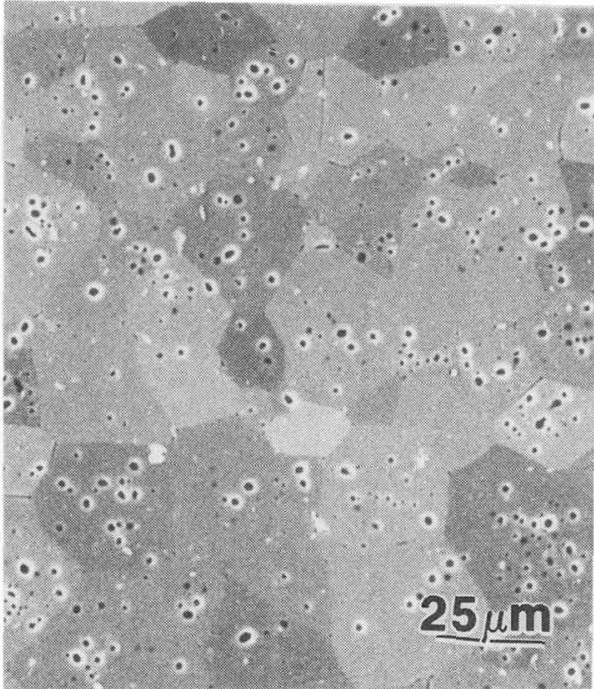

b

Fig. 5 Scanning electron micrographs of (a) SHS/DC and (b) hot-pressed titanium carbide.

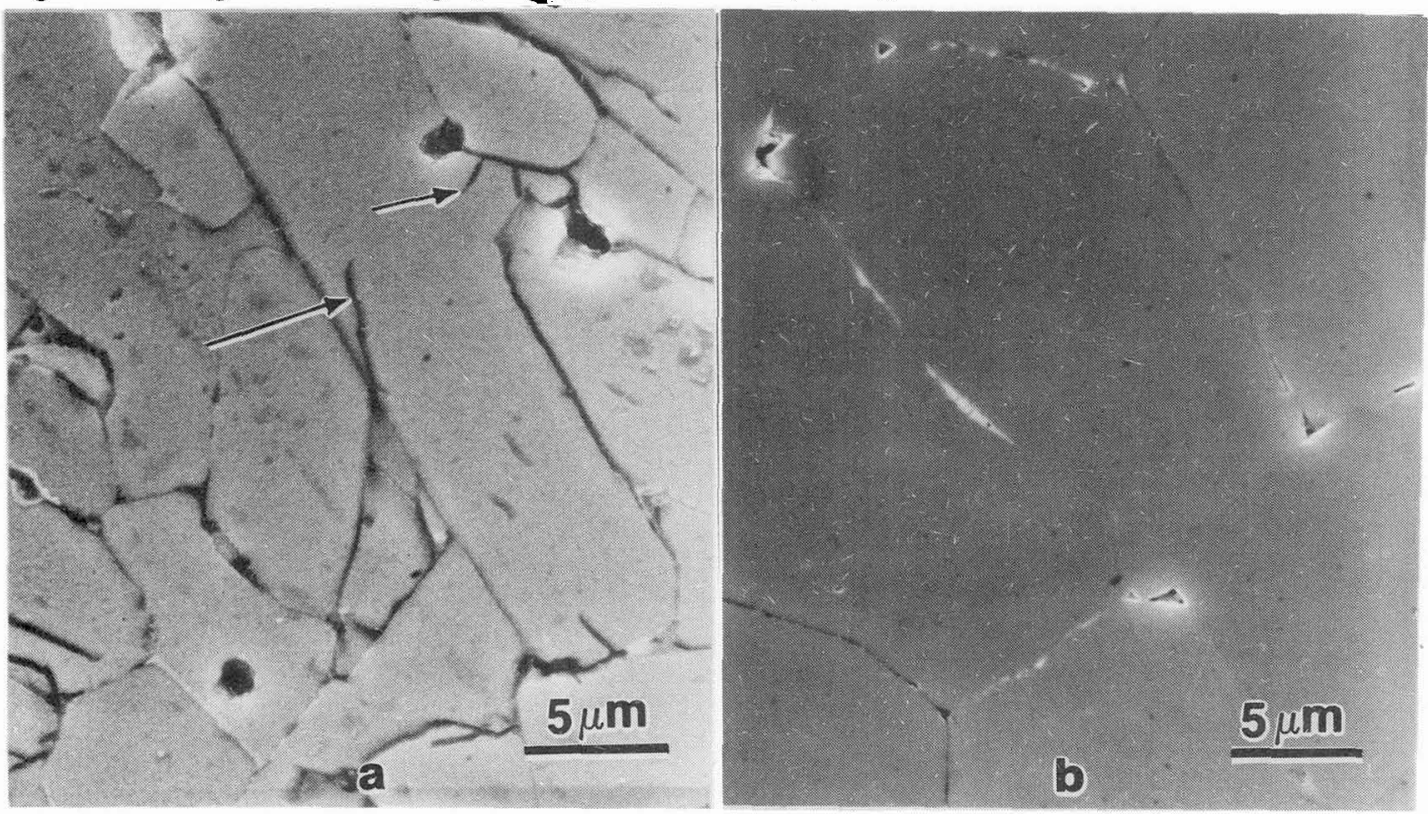

Fig. 6 Scanning electron micrographs of (a) SHS/DC titanium diboride and (b) $\mathrm{TiB}_{2}+1.5$ wt\% Ni. 


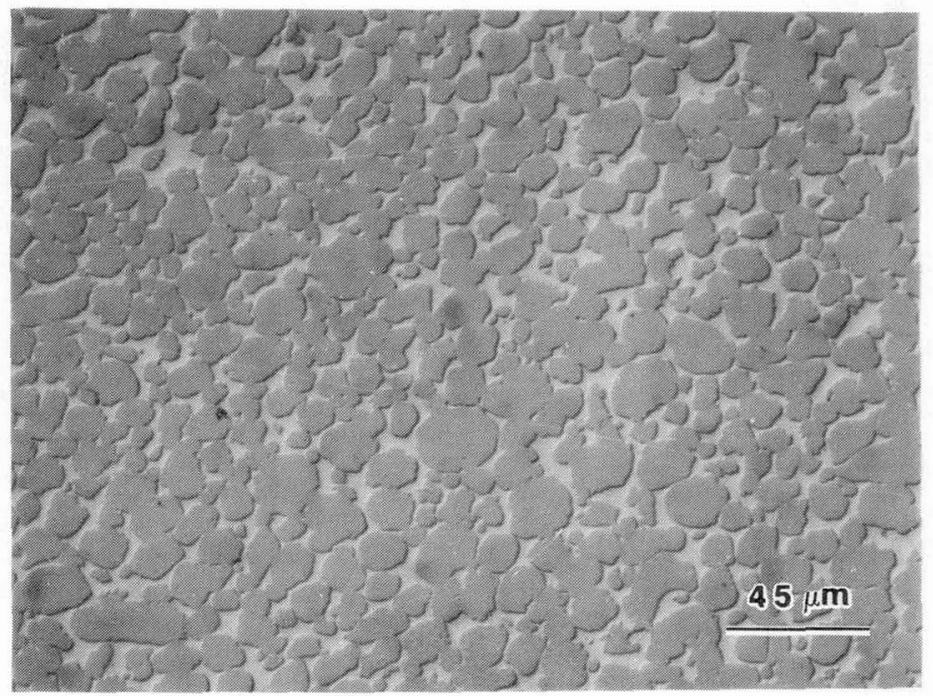

a

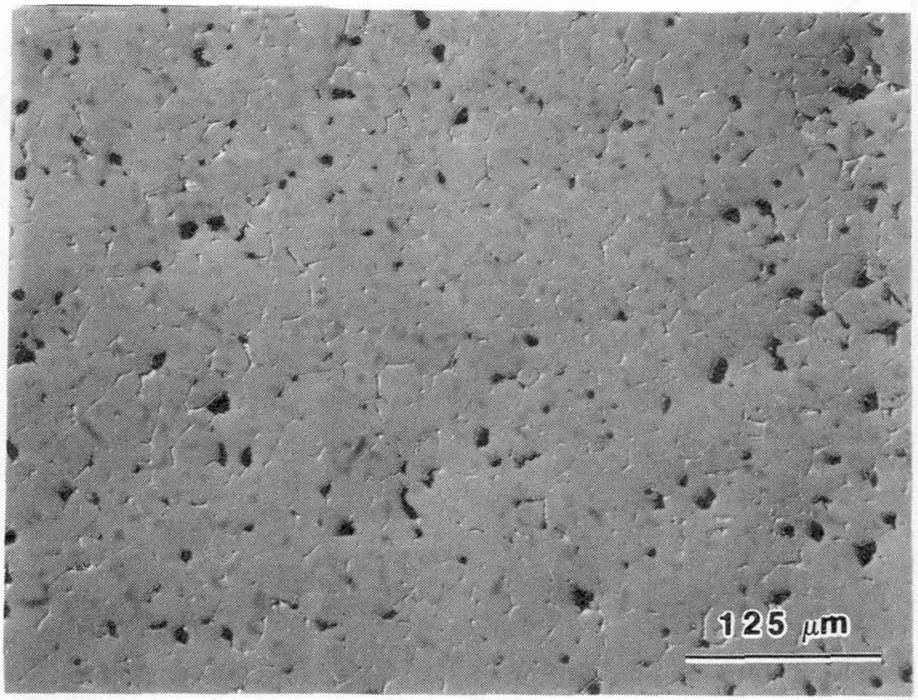

b

Fig. 7 Optical micrographs of (a) TiC $+20 w t \% ~ N i$ and (b) $\mathrm{TiC}+5 \mathrm{wt} \% \mathrm{Ni}$. 


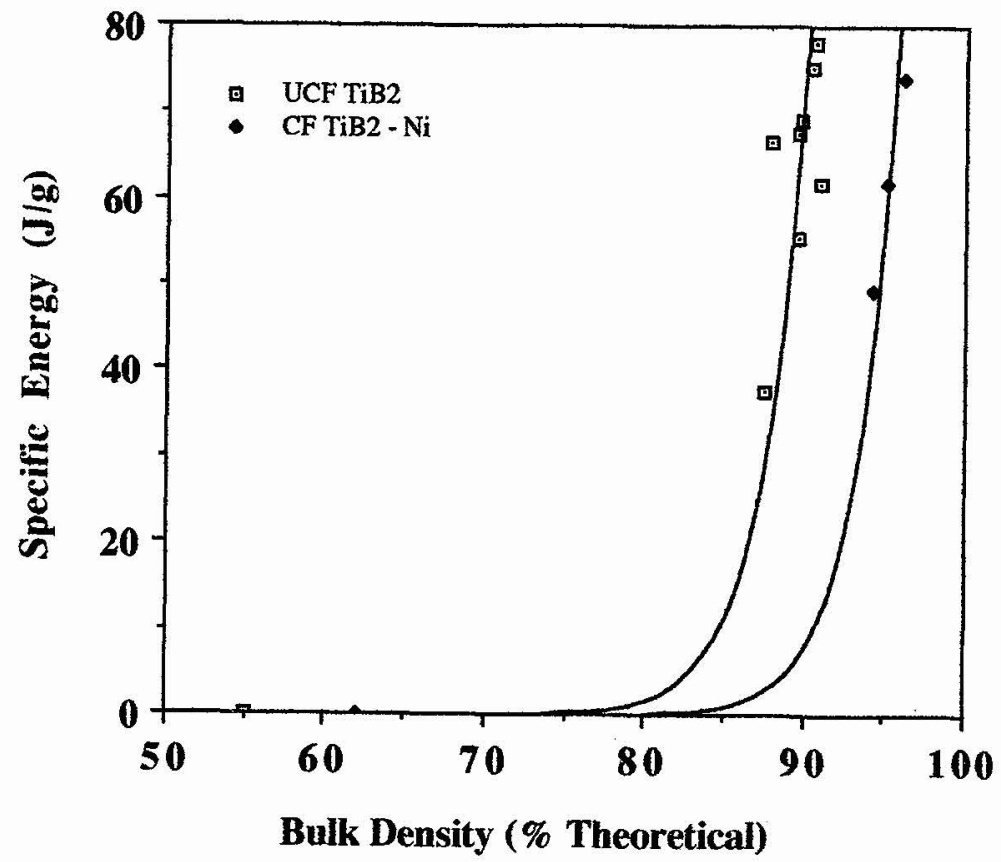

Fig. 8 Densities achieved for $\mathrm{TiB}_{2}$ versus DYNAPAK energy.

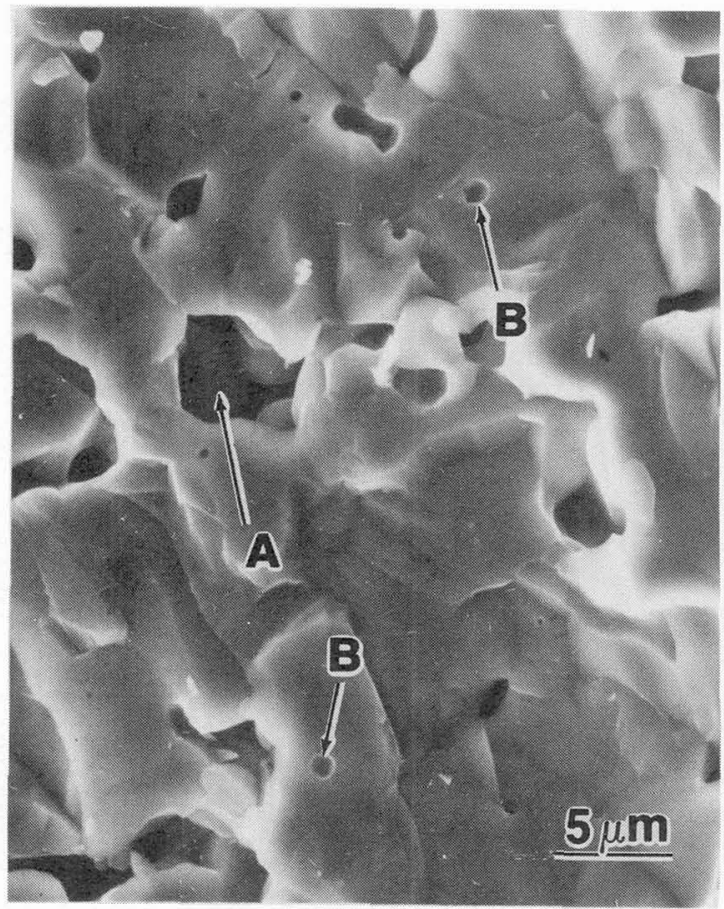

a

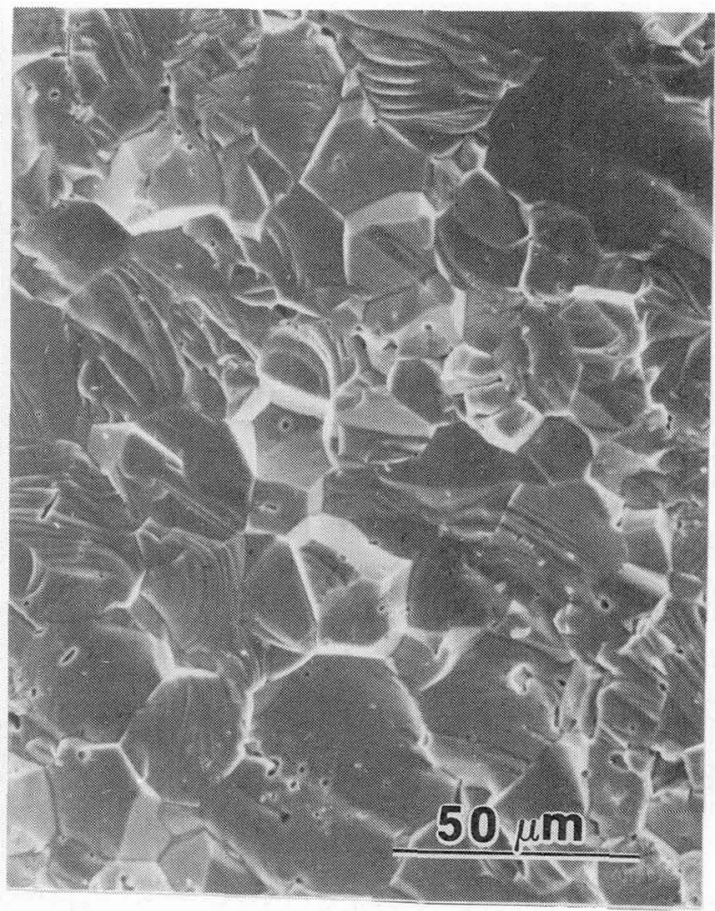

b

Fig. 9 Scanning electron micrographs of (a) $\mathrm{TiB}_{2}$ and (b) $\mathrm{TiC}$ fractured at high strain rates. 
Table I Mechanical Properties (Compressive) of SHS/DC TiC and TiB 2 .

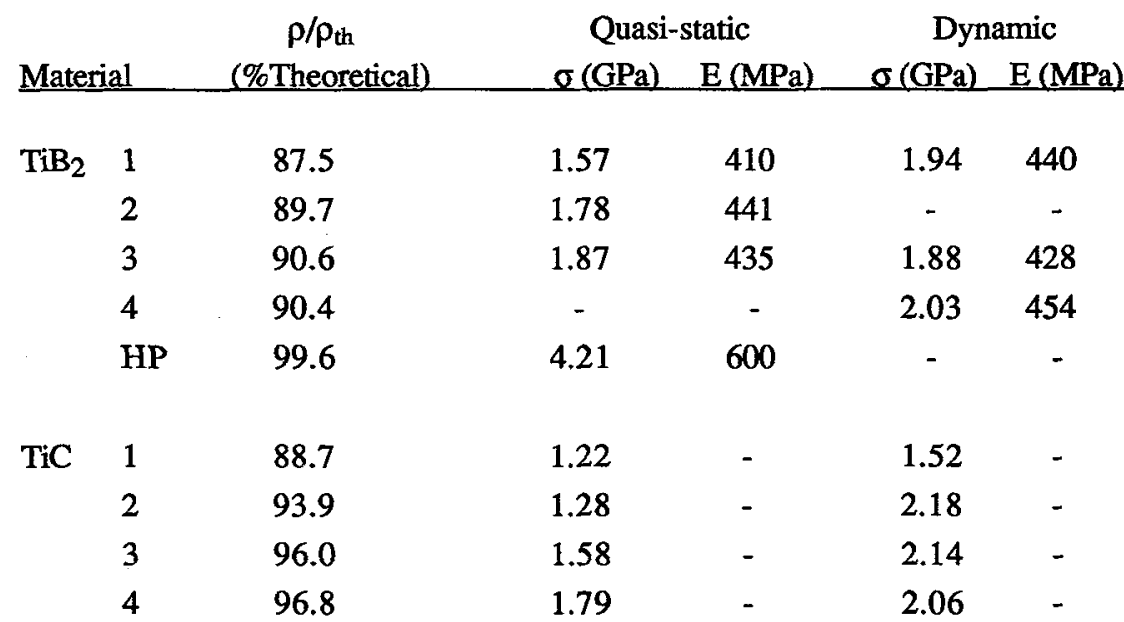

The dynamic $\left(\sim 10^{2} \mathrm{~s}^{-1}\right)$ compressive strength of $\mathrm{TiB}_{2}$ is slightly higher than the quasistatic one. This strength is less than one half of that of the hot-pressed product. The elastic modulus of the SHS/DC TiB 2 is only two-thirds of that of the hot-pressed material. These differences are due to the presence of voids (density: 87.5 - 90.4\% TD) and microcracks in the SHS/DC product. The SHS/DC TiC showed dynamic compression strength that was approximately $20 \%$ higher than the quasistatic one. For the material with $\sim 96 \% \mathrm{TD}$, the quasistatic and dynamic strengths are $\sim 1.7$ and $2.1 \mathrm{GPa}$, respectively.

The fracture surfaces were primarily transgranular for both $\mathrm{TiB}_{2}$ and $\mathrm{TiC}$. Figure 9 shows typical dynamic fracture surfaces. The cleavage cracks, through the grains are evident. Two types of pores exist in $\mathrm{TiB}_{2}$. They are marked $\mathrm{A}$ and $\mathrm{B}$ in Figure 9. Type $\mathrm{A}$ voids are larger and are primarily at the grain boundaries and triple points. Smaller voids, with faceted sides due to the anisotropy of the surface energy, reside primarily at the grain interiors (arrow B). The transgranular nature of the fracture confirms the observations by Vecchio et al. $/ 3 /$ that the grain boundaries are free of impurities and second phases.

\section{Acknowledgements}

This research was supported by the U. S. Army Research Office Contract No. DAAL-03-88-K-0194. The help of Mr. J. C. LaSalvia and of Mr. Klaus Bluegill is gratefully acknowledged. Mr. John Isaacs performed some of the dynamic tests and we thank him for his contribution. The use of the facilities of the Center of Excellence for Advanced Materials is acknowledged. Mr. Richard Polycka, President, CERCOM, kindly provided us the hot-pressed TiC and $\mathrm{TiB}_{2}$ specimens.

\section{References}

/1/ MERZHANOV, A. G., in "Combustion and Plasma Synthesis of High-Temperature Materials", VCH Publishers, New York, p. 1, 1990.

2/ MUNIR, Z. A., and ANSELMI-TAMBURINI, U., Mater. Sci. Rep., 3 (1989) 227.

B/ NIILER, A., KECSKES, L. J., KOTTKE, T., NETHERWOOD, JR., P. H., and BENCK, R. F., Technical Report BRL-TR-2951, Ballistic Research Laboratory, Aberdeen Proving Ground, MD, Dec., 1988.

14/ VECCHIO, K. S., LASALVIA, J. C., MEYERS, M. A., and GRAY III, G. T., "Microstructural Characterization of SHS/Dynamically Compacted and Hot-Pressed Titanium Carbides," to be published, 1991. 